\title{
Editorial: The Times They Are A-Changin'
}

It may be only a coincidence that so many changes seem to be taking place in 2009. For researchers on Canada's elderly population and indeed for the international gerontological research community, I believe the world-wide recession is going to challenge us to reconsider many of the assumptions on which our research has been predicated over the past few decades. Let me mention just a few.

We have generally assumed that poverty among the elderly population was in decline as incomes and government transfers improved. What impacts will the massive declines in global stock markets, the collapse of real estate prices in many places, and the impacts and the responses of governments at all levels have on the coming cohorts of the elderly population? Instead of analysing trends assuming that early retirement or retirement at age 65 is increasingly the norm, what will be the implications of forced retirement, people working beyond the age of 65 , and retired persons needing to return to work because they cannot afford to live on the savings and pensions that a few years ago they assumed would be more than sufficient to meet the aspirations in their later years? Instead of analysing trends assuming shorter work weeks, will we need to consider informal caregivers who are working longer hours and have fewer hours to provide help? Instead of assuming that the trend towards life expectancy with more years disability-free, will we need to consider a growing elderly population who because of the stress induced by these uncertain times have more mental and physical health problems? If these changes and others overthrow the norms on which we have developed our prescriptions, what will be the implications for the health and social care systems we have sought to improve?

At this point in time, it is difficult to tell whether the changes suggested above and indeed many others not mentioned will be short- or long-term. Even in the short term, the challenges, however, will be great for our elderly populations. We in the research community need to consider whether the theories, models, and methods on which research has been predicated in the past have to be adjusted. Or do we need new theories, models, and methods to understand and explain the changes taking place and to contribute to public policies that will reduce the negative impacts on our elderly populations as the effects of the world-wide recession become increasingly evident?

Just as we will need to rethink our theories and models for research, the Canadian Journal on Aging/La revue canadienne $d u$ vieillissement $(C J A / R C V)$ has gone through a process of rethinking its future strategies for improving the dissemination of our research efforts. With this issue and volume, we switch to our new publisherCambridge University Press (CUP). While I am confident that the change to CUP will mean improvements in service both for our readers and authors, the change that excites me most is $C J A / R C V$ will become a truly international journal. What will this actually mean for authors and readers?

There can be no doubt that $C J A / R C V$ will continue to be the premiere venue for the publication of refereed research on Canada's aging population by our most gifted researchers. What will change is that the audience will expand to an international audience because of CUP's world-wide network of distribution and marketing. With the journal's more high-profile presence internationally, readers can also expect to see more articles from leading international researchers in the pages of $C J A / R C V$. While there are likely to be some "bumps along the road" as these changes take place, I am confident that the changes $C J A / R C V$ is making with our new publisher will strengthen the journal as we move forward. Yes, "the times they are a-changin" and with them our research and journal must also change.

As always, please contact me at mark.rosenberg@ queensu.ca if you have any thoughts about this editorial or any other aspect of $C J A / R C V$.

Mark Rosenberg

Editor-in-Chief 